\title{
Kajian Undang-undang Cagar Budaya Tahun 2010 Dari Sudut Pandang Pengelolaan World Heritage
}

\author{
Oleh : \\ Nahar Cahyandaru, S.Si \\ Balai Konservasi Peninggalan Borobudur
}

Undang-undang cagar budaya pengganti Undang-Undang No.5 tahun 1992 yang telah lama dinantikan kehadirannya akhirnya selesai disahkan pada tahun 2010 ini. Berbagai harapan akan terwujudnya peningkatan efektivitas dan kualitas pengelolaan cagar budaya di Indonesia semakin mengemuka. Banyak perubahan dan kemajuan yang ada dalam Undang-undang yang baru ini dibandingkan dengan Undang-undang yang lama.

Tulisan ini bermaksud untuk menganalisis Undangundang Cagar Budaya tahun 2010 dari sudut pandang pengelolaan warisan dunia (World Heritage). Analisis dimaksudkan untuk menemukenali berbagai kesesuaian konsep pelestarian, dan untuk mengetahui apakah Undangundang tersebut cukup memadai (adequate) untuk mendukung operasional world beritage di Indonesia. Tentu saja tulisan ringkas ini tidaklah cukup untuk membuat kesimpulan yang bernilai ilmiah tinggi karena tidak dilakukan dengan penelitian yang mendalam melainkan hanya berdasar identifikasi-identifikasi data saja.

Indonesia sebagai negara anggota $\mathrm{PBB}$ dan juga anggota UNESCO turut berperan aktif dalam kebijakan internasional yang dikeluarkan UNESCO. Dalam kaitannya dengan pelestarian warisan budaya, Indonesia telah meratifikasi konvensi dunia tentang pelestarian warisan dunia budaya dan alam (Convention Concerning the Protection of World Cultural and Natural Heritage) yang dirumuskan oleh UNESCO tahun 1972. Ratifikasi telah dilakukan sejak
1989, dan kemudian diikuti dengan penetapan beberapa situs di Indonesia sebagai warisan dunia. Hingga saat ini Indonesia telah memiliki tujuh warisan dunia (3 warisan budaya dan 4 warisan alam).

Sebagai negara yang telah meratifikasi konvensi dunia tentang pelestarian warisan dunia budaya dan alam, maka Indonesia tunduk dengan aturan-aturan yang digariskan dalam konvensi maupun aturan pendukung dalam Guideline yang dikeluarkan. Oleh karena itu sudah semestinya jika Undangundang Cagar Budaya yang berlaku di Indonesia sejalan dengan prinsip dan konsep pelestarian yang digariskan dalam konvensi. Lebih lanjut Undang-undang yang berlaku juga harus mampu mendukung operasional konvensi berupa aturan pengelolaan situs-situs yang telah ditetapkan sebagai warisan dunia maupun situs yang akan diajukan (Tentative list). Berikut ini akan dikemukakan beberapa hal yang akan dianalisis keterkaitannya antara pasal-pasal yang ada dalam UndangUndang Cagar Budaya tahun 2010 dan prinsip serta konsep pengelolaan warisan dunia.

\section{A. Tujuan Pelestarian}

Bagian awal dari suatu aturan adalah tujuan dari diadakannya aturan tersebut. Dalam Undang-undang yang lama (No.5 tahun 1992) belum diatur dengan jelas tujuan pelestarian, sedangkan dalam Undang-undang yang baru sudah disebutkan secara lebih jelas dan terperinci. Data perbandingan tujuan pelestarian dapat ilihat pada tabel berikut :

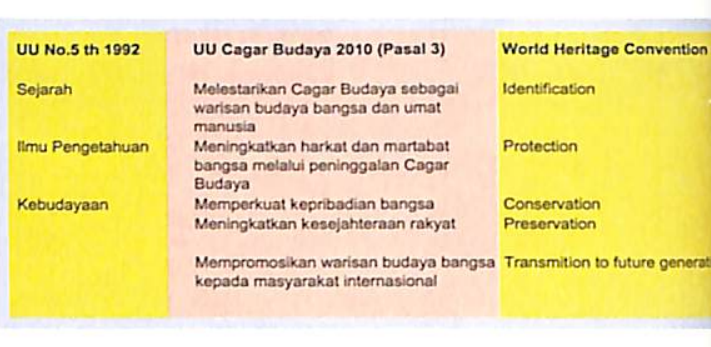

Berdasarkan tabel perbandingan di atas dapat diketahui bahwa tujuan-tujuan pelestarian dalam world beritage sudah terakomodasi dalam Undangundang Cagar Budaya tahun 2010. Meskipun dengan bahasa yang berbeda dan khas untuk Indonesia, namun poin-poin kunci dalam tujuan konvensi tersebut telah terakomodasi.

\section{B. Cakupan Cagar Budaya}

Perbedaan lain antara Undang-undang Benda Cagar Budaya No.5 tahun 1992 dengan Undang-undang Cagar Budaya tahun 2010 adalah cakupan cagar budaya, dimana Undang-undang yang baru lebih luas. Pada UU yang lama hanya disebutkan benda, situs, dan kawasan. Namun dalam UU Cagar Budaya 2010 Bab III (pasal 511) meliputi Benda, Bangunan, Struktur, Situs, dan Kawasan. UU yang baru membedakan antara bangunan dan struktur, karena dalam kenyataannya cagar budaya banyak yang tidak berupa bangunan melainkan struktur. Dalam world beritage convention bangunan dan struktur disebut sebagai monumen. Hal yang berbeda dalam hal ini adalah adanya kriteria kelompok bangunan yang secara tegas dibedakan dalam konvensi namun tidak dibedakan dalam UU. Meskipun hal ini membawa konsekuensi perbedaan cara 
pelestarian dan pengelolaan, namun secara operasional masih bisa dilaksanakan secara sejalan. Berikut ini tabel perbandingan cakupan cagar budaya yang tercantum dalam UU BCB 1992, UU CB 2010, dan konvensi.

\begin{tabular}{|c|c|c|}
\hline $\begin{array}{l}\text { JU Na.5 th } 1992 \\
\text { Benda buatan manusia } \\
\text { Banda alam } \\
\text { Stus } \\
\text { Camasan Cogar Budaya }\end{array}$ & 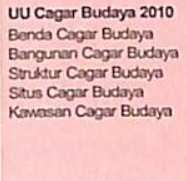 & $\begin{array}{l}\text { World Heritage Corvention } \\
\text { Monumen } \\
\text { Kumpulan Bangunan } \\
\text { Stitus } \\
\text { Cutural Landscapo (SajjanManskap budaya) } \\
\text { Bentuk Khusus } \\
\text { : Kanal } \\
\text { - Kota Bersejarah } \\
\text { Jalur Bersejarah }\end{array}$ \\
\hline
\end{tabular}

Perbedaan lainnya adalah kriteria cultural landscape, pada konvensi yang disebut cultural landscape adalah suatu kawasan cagar budaya yang antara situs dengan aspek intangible beritage menyatu menjadi kesatuan yang hidup berdampingan dan sinergis. Dalam UU Cagar Budaya pengertian kawasan adalah kumpulan beberapa situs yang lokasinya berdekatan, jadi lebih bersifat geografis dan belum memperhatikan aspek intangible beritage. Meskipun sudah tercantum kata-kata lanskap budaya, namun ternyata memiliki pengertian yang berbeda. Dalam penjelasan Undang-undang disebutkan lanskap budaya adalah bentang alam hasil bentukan manusia yang mencerminkan pemanfaatan situs atau kawasan pada masa lalu.

Hal lain yang belum tercantum secara tegas dalam UU adalah bentuk khusus (seperti kanal, kota bersejarah, jalur bersejarah, dll) yang secara fisik bukanlah bangunan, struktur, atau monumen. Namun hal ini bukan menjadi masalah karena UU masih membuka masuknya kriteria ini melalui pasal 11 mengenai cagar budaya yang memiliki arti khusus bagi masyarakat atau bangsa Indonesia. (Pasal 11: "Benda, bangunan, struktur, lokasi, atau satuan ruang geografis yang atas dasar penelitian memiliki artikhusus bagi masyarakat atau bangsa
Indonesia, tetapi tidak memenuhi kriteria Cagar Budaya sebagaimana dimaksud dalam pasal 5 sampai dengan pasal 10 dapat diusulkan sebagai Cagar Budaya".)

\section{Pemeringkatan Cagar Budaya}

Salah satu hal terpenting dalam UU cagar Budaya tahun 2010 adalah adanya pemeringkatan. Dengan adanya pemeringkatan maka akan menjadi jelas cagar budaya masuk sebagai cagar budaya tingkat nasional, provinsi, atau kabupaten. Hal ini merupakan kebutuhan mendasar yang selama ini belum tercantum dalam UU BCB No.5 tahun 1992.

Konvensi UNESCO mensyaratkan bahwa situs yang diajukan sebagai world heritage minimal harus masuk sebagai warisan budaya nasional. Jika pemeringkatan ini belum dibuat akan menyulitkan proses pengajuan karena tidak jelas cagar budaya yang bersangkutan telah masuk sebagai cagar budaya tingkat nasional atau tidak. Selama ini dasar pengakuan sebagai cagar budaya nasional didasarkan pada keputusan benda cagar budaya pada saat penetapan, bukan berdasar proses pemeringkatan. Dengan adanya pemeringkatan yang dilakukan oleh tim ahli dan dimasukkan dalam register nasional, dasar pengajuan n'orld heritage menjadi lebiih jelas.

\section{Kriteria Cagar Budaya}

Kemajuan yang sangat penting dalam UU Cagar Budaya tahun 2010 adalah adanya kriterian cagar budaya. Selain harus berusia sekurang-kurangnya 50 (lima puluh) tahun atau mewakili masa gaya sekurang-kurangnya berusia 50 (lima puluh) tahun; dan/atau memiliki arti khusus bagi sejarah bangsa, terdapat kriteria untuk masule cobagar cagar hudasa nasional. Di sini penulis mencoba memperbandingkan antara kriteria cagar budaya nasional menurut UU Cagar Budaya tahun 2010 dengan kriteria Outstanding Universal V alue yang merupakan syarat suatu situs dapat diajukan sebagai world heritage.

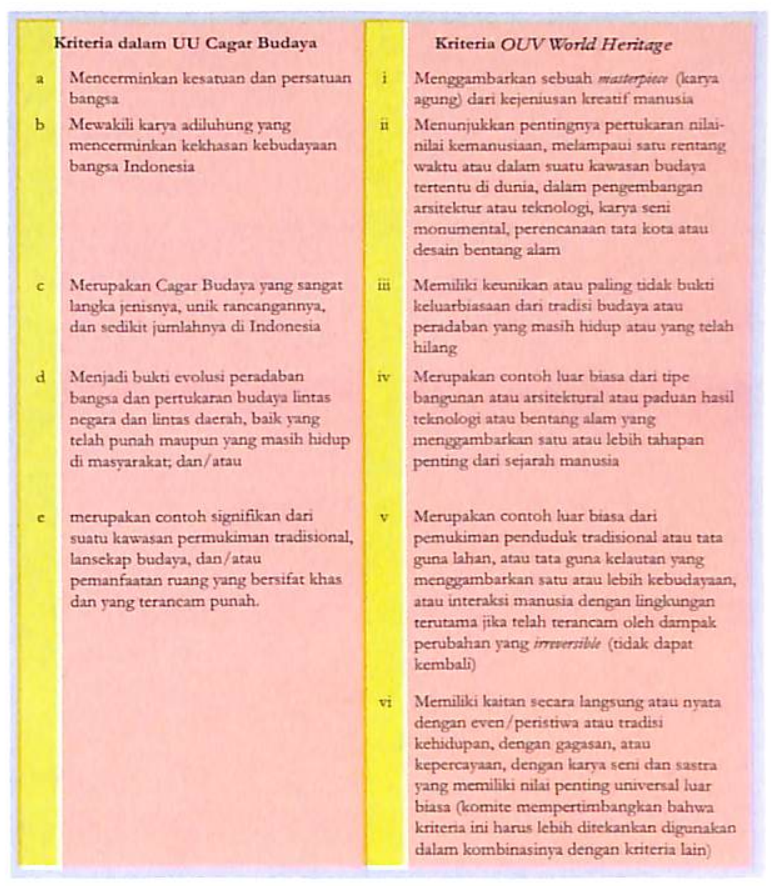

Dari tabel tersebut dapat dilihat adanya kesesuaian antara kriteria cagar budaya menurut UU dan kriteria OUV. Tentu saja kriteria cagar budaya nasional sangat nasional atau keindonesiaan sifatnya, sehingga kriteria a dalam UU adalah mencerminkan persatuan dan kesatuan bangsa. Berikutnya kita bis a memperbandingkan antara kriteria b dalam UU dengan kriteria i $O L I$ yaitu masterpiece atau karya adiluhung. Selanjutnya kriteria c dalam UU dengan kriteria ii dan iii dalam OLI vaitu sejalan dalam hal keunikan dan rancangan. Kriteria d dalam LU juga sangat sejalan dengan kriteria iv dalam OL'T , vaitu sebagai bukti evolusi atau tahapan sejarah/peradaban. Demikian juga dengan kriteria e dalam L'L vang sejalan dengan kriteria y dalam () I l vatu sebagai contoh luar hiasa dalam hal pemukiman, tata 
guna lahan dan ruang. Namun sayang kriteria vi dalam $O U V$ yang lebih banyak berbicara aspek intangible tidak terakomodasi secara eksplisit sebagai kriteria dalam UU Cagar Budaya

\section{E. Kebijakan}

Sebagai sebuah produk hukum yang berusia cukup lama (sejak 1972) konvensi UNESCO mengalami berbagai perkembangan interpretasi. Interpretasi konvensi agar dapat diterapkan oleh para negara anggotanya adalah dengan adanya guideline yang selalu direvisi setiap beberapa tahun. Berbagai macam kebijakan juga mengalami perkembangan sesuai perkembangan jaman. Kebijakan 5C UNESCO yang dirumuskan pada sidang umum tahun 2002 dan disempurnakan tahun 2007 adalah :

1. Credibility

2. Conservation

3. Communication

4. Capacity Building

5. Community' Involvement

Undang-undang Cagar

Budaya tahun 2010 juga mengalami beberapa perubahan dan kemajuan sesuai dengan tuntuan kebutuhan pelestarian saat ini. Dibandingkan dengan UU yang lama beberapa perubahan dan kemajuan yang tercantum dalam UU Cagar Budaya tahun 2010 antara lain adalah :

1. Pelibatan masyarakat

Pelibatan masyarakat yang dalam LU BCB tahun 1992 belum banyak disinggung pada LU Cagar budaya ini cukup banyak diatur. Pelibatan masyarat merupakan kebijakan penting yang harus diambil dalam pelestarian, oleh karenanya penting untuk diatur.

2. Pembagian peran dan kewenangan pemerintah pusat dan pemerintah daerah

Adanya pembagian peran dan kewenangan yang jelas antara pemerintah pusat dengan pemerintah Provinsi dan Kabupaten akan meningkatkan efektivitas pelestarian cagar budaya. Hal ini juga didukung dengan adanya pemeringkatan sehingga pembagian kewenangan semakin jelas.

3. Peningkatan kualitas SDM Sumber daya manusia juga menjadi faktor yang diperhatikan dalam UU Cagar budaya, hal ini tercermin antara lain dengan adaya tim ahli di tiap-tiap kabupaten/kota, provinsi, maupun tingkat nasional. Selain itu juga adanya tenaga ahli dan pelaksana pelestarian. Adanya pengaturan mengenai SDM tersebut membawa konsekuansi harus diadakannya peningkatan kualitas SDM di seluruh Indonesia.

4. Register nasional

Register nasional sangat penting sebagai daftar acuan seluruh cagar budaya yang dimiliki Indonesia. Register nasional akan meningkatkan kredibilitas cagar budaya serta jaminan kelestariannya. Adanya aturan yang jelas dalam penghapusan juga meningkatkan kredibilitas cagar budaya.

5. Pelindungan, Pengembangan, Pemanfaatan

Pelindungan meliputi penyelamatan, pengamanan, zonasi, pemeliharaan, pemugaran. Pengembangan meliputi penelitian, revitalisasi, dan adaptasi. Pemanfaatan Cagar Budaya dapat dilakukan untuk kepentingan agama, sosial, pendidikan, ilmu pengetahuan, kebudayaan, dan pariwisata.

6. Insentif

Selama ini perorangan yang memiliki cagar budaya sering terikat dengan berbagai aturan namun tidak diimbangi dengan insentif dan penghargaan yang sepadan. UU Cagar budaya mengatur adanya insentif dan penghargaan ini sehingga pemilik menjadi lebih terdorong untuk ikut melestarikan.

7. Larangan dan sanksi

Larangan dan sanksi yang tegas juga dapat meningkatkan efektivitas pelestarian dan memberikan efek jera bagi orang yang merusak cagar budaya.

Berdasar uraian singkat diatas sudah cukup banyak usaha peningkatan bagi pengaturan pelestarian cagar budaya, yang sebagian besar juga telah sejalan dan mendukung kebijakan $5 \mathrm{C}$ UNESCO. Namun ada satu kebijakan yang masih kurang diatur secara tegas dalam UU yaitu communication. Komunikasi dengan masyarakat sangat penting dalam menyebarluaskan nilai penting cagar budaya agar tujuan pelestarian yang telah digariskan di atas dapat terwujud. Komunikasi juga penting untuk menumbuhkan kesadaran dan kepedulian masyarakat (public awareness).

\section{F. Penutup}

Berdasarkan uraian analisis di atas maka dapat disimpulkan bahwa Undang-undang Cagar Budaya tahun 2010 sudah sejalan dengan prinsip dan konsep pengelolaan world beritage yang digariskan dalam konvensi. Undang-undang ini juga sudah cukup memadai untuk mendukung pengelolaan world beritage yang sudah dimiliki oleh Indonesia serta warisan budaya lain yang ke depan dapat diajukan sebagai world beritage.

Beberapa hal ada yang belum terakomodasi secara memadai dalam L'ndang-undang yaitu mengenai aspek intangible beritage yang belum banyak diatur, 
terutama dalam keterkaitan antara situs dengan intengible beritage. Hal ini tercermin dalam cakupan cagar budaya yang mengatur sampai dengan kawasan cagar budaya. Sedangkan world heritage convention mengatur hingga cultural landscape yang didalamnya ada aspek kawasan dan aspek intangible beritage di dalamnya. Di samping itu UNESCO juga memiliki konvensi lain dalam perlindungan terhadap warisan dunia intangible (Convention for the Safeguarding of the Intagible Cultural baritage). Kekayaan cagar budaya intangible di Indonesia juga sangat tinggi, sehingga perlu upaya perlindungan yang memadai agar tetap lestari.
Komunikasi juga menjadi hal yang masih perlu ditingkatkan untuk memperkuat tujuan pelestarian cagar budaya, yaitu untuk memperkuat kepribadian bangsa, meningkatkan harkat dan martabat bangsa, serta mempromosikan warisan budaya bangsa kepada masyarakat internasional. Hal-hal tersebut dapat terwujud melalui sistem komunikasi publik yang memadai. Oleh karena itu pengaturan aspek komunikasi perlu diperkuat dalam pelaksanaan UU, misalnya dengan pengaturan yang lebih lengkap dalam Peraturan Pemerintah.

$$
\text { Analisis di atas }
$$

menunjukkan bahwa secara umum
Undang-undang cagar budaya tahun 2010 sudah sejalan dan sudah memadai pengelolaan world heritage di Indonesia. Namun pasal yang paling jelas mendasari pengelolaan world heritage adalah pasal 46, yang berbunyi "Cagar budaya peringkat nasional yang telah ditetapkan sebagai Cagar Budaya Nasional dapat diusulkan oleh Pemerintah menjadi warisan budaya dunia". Pasal ini 46 ini menunjukkan secara jelas bahwa Undang-undang ini telah disusun dengan mengakomodasi konsep world beritage. 区

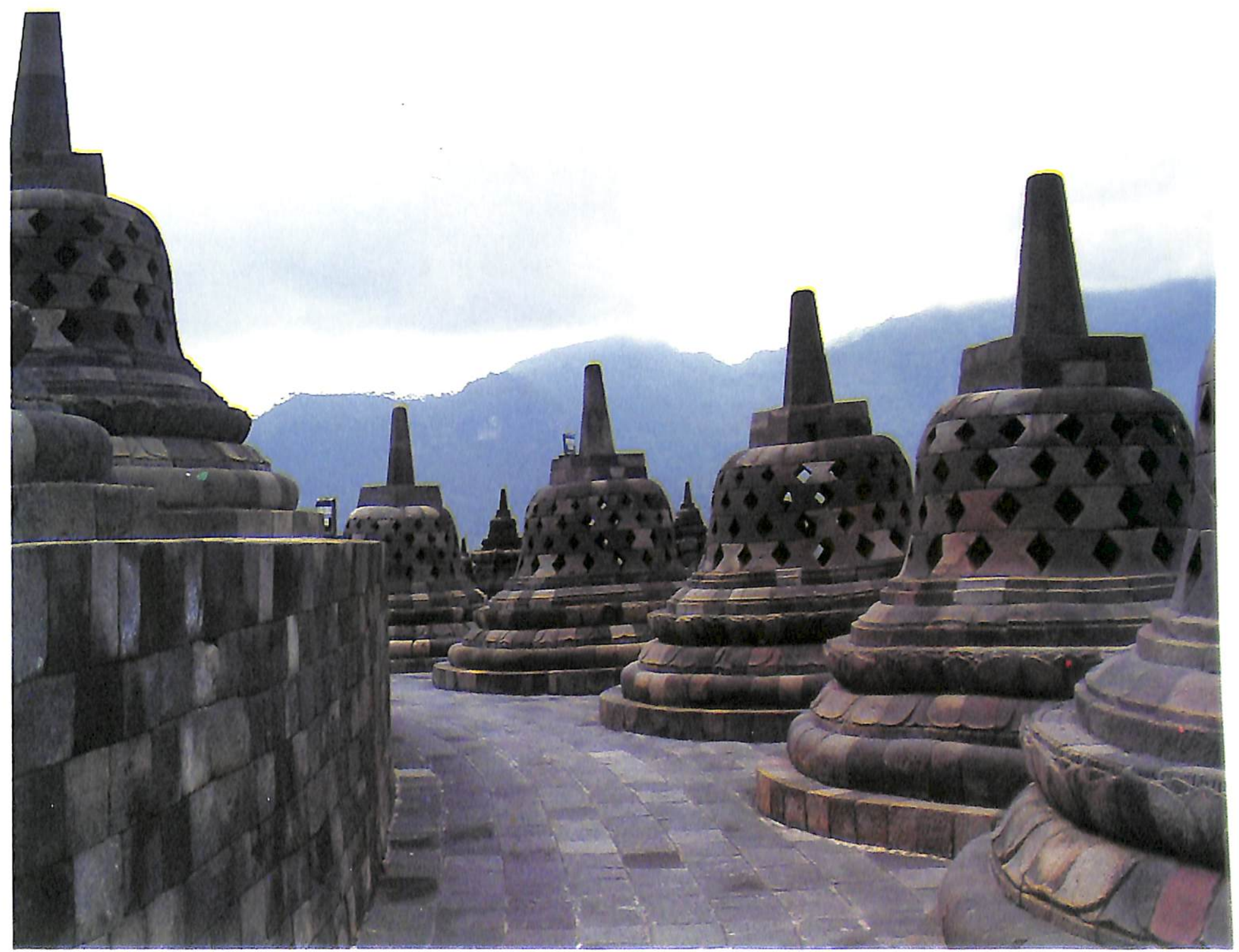

